\title{
Eco-friendly Route for Thermoplastic Polyurethane Elastomers with Bio-based Hard Segments Composed of Bio-glycol and Mixtures of Aromatic-Aliphatic and Aliphatic-Aliphatic Diisocyanate
}

\author{
Ewa Głowińska ${ }^{1}$ (1) $\cdot$ Wojciech Wolak ${ }^{1} \cdot$ Janusz Datta ${ }^{1}$ \\ Accepted: 26 November 2020 / Published online: 5 January 2021 \\ ○ The Author(s), under exclusive licence to Springer Science+Business Media, LLC part of Springer Nature 2021
}

\begin{abstract}
Application of bio-based diisocyanates with low volatility instead petrochemical diisocyanates has positive impact on environment by reduction of hazardous effects on living organisms and lead to bio-based polyurethanes (bio-PUs) with good usage properties. This work was focused on the synthesis and chosen properties examination of partially bio-based thermoplastic polyurethane elastomers (bio-PUs) obtained using diisocyanate mixtures, polytetrahydrofurane (PolyTHF) and bio-1,3-propanediol (bio-PDO). Two types of diisocyanate mixtures were prepared as follows: aliphatic-aliphatic based on hexamethylene diisocyanate with partially bio-based aliphatic diisocyanate Tolonate ${ }^{\mathrm{TM}}$ X FLO 100 (HDI-FLO) and aromatic-aliphatic based on diphenylmethane diisocyanate with partially bio-based diisocyanate (MDI-FLO) with reduction of 25 mass\% of petrochemical diisocyanate. Bio-PUs were obtained via prepolymer method. Thermoplastic polyurethane elastomers have been examined in the terms of chemical structure and thermal, thermomechanical, mechanical and physicochemical properties. Bio-PU based on HDI-FLO diisocyanate mixture exhibited higher thermal stability. The beginning of thermal decomposition took a place at lower temperature ca. $30^{\circ} \mathrm{C}$ ) and lower rate than the MDI-PU based materials. DMA analysis showed that HDI-FLO based polyurethanes exhibited greater capacity to accumulate energy and higher stiffness. Both materials characterized similar tensile strength and hardness, but with difference that TPU based on HDI-FLO relieved greater elongation at break about $360 \%$ reached $813 \%$. Taking into account versatile properties of bio-TPU, these material can find application in many branches of industry.
\end{abstract}

Keywords Environmental friendly synthesis · Thermoplastic polyurethane elastomers · Bio-based diisocyanates · Diisocyanate mixtures $\cdot$ Low volatility diisocyanate

\section{Introduction}

Incontestably polyurethanes belong to the one of the most investigated polymers which have a wide range of application due to their unique mechanical, physical, chemical and biological properties. These materials combine durability and hardness of metals with elasticity of rubber. Currently, the trends in the developments of polyurethane materials synthesis include application of products from recycling or raw materials of vegetable origin, and the fabrication of

Ewa Głowińska

ewa.glowinska@pg.edu.pl

1 Department of Polymer Technology, Chemical Faculty, Gdańsk University of Technology, G. Narutowicza Street 11/12, 80-233 Gdańsk, Poland polyurethanes composites with different fillers usage [1]. Because of growing interest in an environment friendly polymeric materials, many scientist works are focused on conversion polyurethanes into theirs bio-analogue called bio-based polyurethanes (bio-PUs) by using bio-based components to their synthesis. The most significant advantage of bio-PUs is the fact that they can be obtained with the usage of different polyols and isocyanates which resulted in their various types or forms. Typically, polyurethanes properties can be easily modified by changes in their chemical composition by formulation changes or processing conditions. As a result, PUs can be divided into several groups: rigid and elastic foams, thermoplastics, elastomers, coatings, adhesives and fibers.

The scientific works focused on environmentally-friendly substrates used for the polyurethane production are actually related with bio-based polyols, bioglycols and the methods of their synthesis [1-8]. However, in the case of bio-based 
isocyanates or more environment-friendly methods of PU production are not so common [9]. The most popular and commercially available method of synthesis of isocyanates is phosgene route [5]. It consists in the reaction of phosgene (carbonyl dichloride) with amines, amine hydrochlorides, amides, sulfonamides, urea and other nitrogen compounds. Using the phosgene route involves some negative aspects. First of all, phosgene is characterized by high toxicity and the whole process causes formation of hydrogen chloride. Moreover, phosgenation is usually connected with using volatile compounds as solvents. These elements cause major problems with work safety and environment protection issues [5]. Another essential aspect related with isocyanates production is the volatility of petroleum prices. Economic and political issues highly influence the prices of petroleum and petroleum-based compounds, including isocyanates. Only in the first quarter of 2017 the price of diphenylmethane diisocyanate (MDI), one of the most commonly used in industry, increased about $30 \%$ and the growth proceeded in the next months. In January 2018 the MDI price growth was also noticeable [10] and reached the

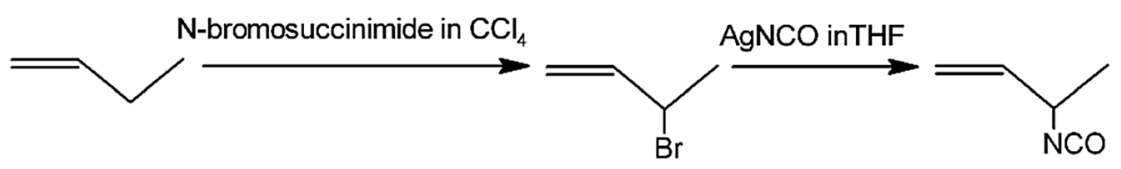

In the second method (scheme 2), oleic acid was converted into diacid and then, as a result of reaction with various compounds, heptamethylene diisocyanate (HPMDI) and 1,16-diisocyanatohexadec-8-ene (HDEDI) were produced $[3,9]$.

$\mathrm{Et}_{3} \mathrm{~N}, \mathrm{THF}$

Ethyl chloroformate, $\mathrm{NaN}_{3}$

$\mathrm{OCN}-\mathrm{R}-\mathrm{NCO}$

Third method is based on transformation methyl diester into dihidrazide and then into acyl diazide. In the next stage, as a result of Curtius rearrangement, isocyanate is formed. This method enabled production of octamethylene diisocyanate (ODI) from castor oil [13].

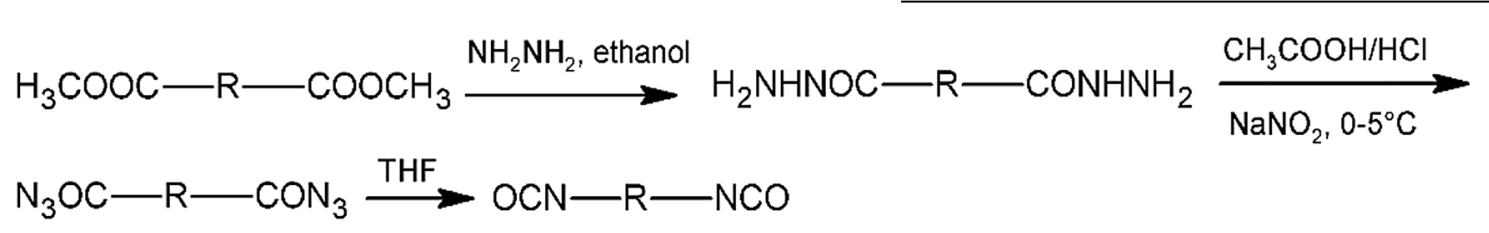


Not only vegetable oils or fatty acids can be used in isocyanates synthesis, but also carbohydrates or amino acids. Starch contained in wastes from industrial crops and food production was used in bio-based pentamethylene diisocyanate (PDI) production. Combination of chemical and biotechnological processes with gas phase technology enabled to obtain the product with $71 \%$ of renewable carbon [14]. Amino acids were also applied in bio-based isocyanate synthesis. The example is L-Lysine that was successfully converted into L-Lysine ethyl ester diisocyanate (LDI). Initial substrate to this reaction was L-Lysine monohydrochloride that was transformed into ester using ethanol. Then, reaction with triphosgene resulted in obtaining the bio-based diisocyanate [15].

Research of [16, 17] showed that polyurethanes obtained using bio-based diisocyanates can equal in the terms of properties with their petrochemical counterparts. Polyurethanes based on bio-based HPMDI exhibit similar mechanical properties and thermal stability in regard to polyurethanes obtained using petrochemical hexamethylene diisocyanate (HDI). Application of HDEDI resulted in production of materials with even better properties. Primarily, tensile strength increased due to higher crosslinking density through hydrogen bonds. Furthermore, PUs synthesized with using bio-based HDEDI were characterized by lower modulus and higher elongation that arose from longer diisocyanates chains.

Application of such bio-based diisocyanates is limited. The main reason is their aliphatic structure, resulting in low reactivity [6]. One of the solution could be preparing mixtures of bio-based diisocyanates with aromatic diisocyanates commonly used in industry like toluene diisocyanate (TDI) or diphenylmethane diisocyanate (MDI). Diisocyanate mixtures are not commonly used in industry and literature regarding to this topic is also limited. One of the examples is application of diisocyanate mixture in the synthesis of polyurethane adhesive/aluminum laminate composites for automotive industry. Mixture of diphenylmethane diisocyanate (MDI) and 4,4'-dicyclohexylmethane diisocyanate $\left(\mathrm{H}_{12} \mathrm{MDI}\right)$ was applied. Obtained composites were characterized by good mechanical properties and high thermal stability [18]. Other example of diisocyanate mixtures using that production of waterborne polyurethanes [16]. The subject of research were diisocyanates commonly used in coatings and adhesives production: isophorone diisocyanate (IPDI), xylene diisocyanate (XDI) and hydrogenated xylene diisocyanate $\left(\mathrm{H}_{6} \mathrm{XDI}\right)$. Polyurethanes based on IPDI and $\mathrm{H}_{6} \mathrm{XDI}$ exhibit good resistance to weather conditions but have low peel strength. In order to improve this parameter, mixtures with XDI-compound improving durability were prepared. The highest tensile strength was obtained using single IPDI, but the highest elongation corresponded to mixture IPDI$\mathrm{H}_{6}$ XDI-XDI with equal amount of every compound [19].
Prisacariu et al. [20] also examined the topic of diisocyanate mixtures. In their work diisocyanates with different geometry were used: diphenylmethane diisocyanate (MDI) and 4,4'-dibenzyl diisocyanate (DBDI). In MDI aromatic rings are connected by one methyl group and it exhibits no symmetry, while in DBDI there are two methyl groupsrotation around bond between these groups enables change of geometry, which results in tendency to crystallization. Five types of polyurethanes were prepared: based on single MDI, single DBDI and three mixtures of them with different order of introduction (first MDI, first DBDI, both diisocyanates at the same time). Thermal and mechanical properties of obtained materials were examined. Polyurethanes based on single DBDI were characterized by the lowest glass transition temperature and the best thermal stability due to the highest degree of crystallinity $(50 \%)$. On the other hand, polyurethanes based on the mixture of MDI and DBDI introduced at the same time, obtained the highest tensile strength and the lowest residual elongation. Inelastic phenomena (highest stiffness, hysteresis and residual elongation) were mostly highlighted when single DBDI was used. Using the diisocyanate mixture allowed to reduce these parameters.

Application of diisocyanate mixtures can also have a good influence on economic and environmental issues. Partial replacement of more expensive diisocyanate with cheaper one, without appreciable decrease in properties, may result in reducing production costs. Environmental issues refer to application of bio-based diisocyanates. Partial replacement of petrochemical diisocyanate with bio-based diisocyanate will lower the utilization of petroleum and limit negative influence on environment. That is why, the aim of the presented research was to examine the chemical structure, thermal, thermomechanical, mechanical and physic-chemical properties of partially bio-based thermoplastic polyurethane elastomers obtained using diisocyanate mixtures including partially bio-based diisocyante. Two types of diisocyanate mixtures were prepared: bio-based aliphatic diisocyanate with petrochemical aliphatic diisocyanate or petrochemical aromatic diisocyanate respectively.

\section{Experimental}

\section{Materials}

Polyetherol as polytertahydrofurane (PolyTHF 2000) with a molecular weight of $\sim 2000 \mathrm{~g} / \mathrm{mol}$ and a hydroxyl value of $56 \mathrm{mg} \mathrm{KOH} / \mathrm{g}$ was purchased from BASF (Germany). Petrochemical aromatic diisocyanate-diphenylmethane diisocyanate (MDI) was provided by BorsodChem (Hungary). Petrochemical aliphatic diisocyanate-hexamethylene diisocyanate (HDI) with NCO content of $49.9 \mathrm{wt} \%$ and partially bio-based diisocyanate derived from palm oil-Tolonate ${ }^{\mathrm{TM}}$ 
X FLO 100 (coded FLO) with NCO content of 12.46 wt\% were supplied by Vencorex Chemicals (France) [21]. As a chain extender bio-based 1,3-propanediol (Susterra ${ }^{\circledR}$ Propanediol, DuPont, USA) was used. Organotin catalystdibutyltin dilaurate (DBTDL) was provided by SigmaAldrich (Poland).

\section{Sample Preparation}

The procedure of partially bio-based thermoplastic polyurethane elastomers preparation was analogous regardless of the type of diisocyanate mixtures: $\mathrm{HDI}-$ Tolonate $^{\mathrm{TM}} \mathrm{X}$ FLO 100 (HDI-FLO) and MDI-Tolonate ${ }^{\mathrm{TM}}$ X FLO 100 (MDIFLO). Partially bio-based polyurethanes were obtained via prepolymer method. Initially, polyol was dried and degassed in temperature $90{ }^{\circ} \mathrm{C}$ for $2 \mathrm{~h}$. Next polyol was cooled to $60{ }^{\circ} \mathrm{C}$ and then diisocyanate mixture was added (HDI-FLO or MDI-FLO). Diisocyanate mixtures were prepared with the weight ratio of petrochemical diisocyanate to bio-based diisocyanate equaled $4: 1$. The prepolymerization reaction was conducted at $80{ }^{\circ} \mathrm{C}$ for $2 \mathrm{~h}$. After prepolymerization reaction the free isocyanate group (NCO) content in the urethane bio-based prepolymer has been determined and was equaled 7.76 and 7.10 for bio-based prepolymer based HDI-FLO and MDI-FLO respectively. In the second stage of the process bio-based prepolymers were cooled to $60{ }^{\circ} \mathrm{C}$ and then mixed with bio-based 1,3-propanediol as a chain extender and with DBTDL catalyst. Samples were prepared in $[\mathrm{NCO}]_{\text {prepolymer }} /[\mathrm{OH}]_{\text {chain extender }}$ molar ratio equaled $1: 1$. Reaction mixtures were degassed under vacuum and gravity cast into heated molds. To complete polymerization process all samples were cured for $24 \mathrm{~h}$ at $100{ }^{\circ} \mathrm{C}$.

\section{Measurements}

Chemical structure of obtained materials was examined by Fourier Transform Infrared Spectroscopy using ATR technique. Analysis was carried out in room temperature by means of Nicolet 8700 spectrophotometer. Spectra were registered in wavenumbers range from 4500 to $500 \mathrm{~cm}^{-1}$ at $4 \mathrm{~cm}^{-1}$ resolution. The degree of phase separation (DPS) was determined as $\mathrm{R} /(\mathrm{R}+1)$, where $\mathrm{R}$ is a carbonyl hydrogen bonding index and expressed as a ratio of absorption intensity of hydrogen-bonded carbonyl and absorption intensity of free carbonyl.

Thermogravimetric analysis (TGA) was performed using a TG 209 F1 Libra Netzsch analyzer under nitrogen atmosphere at a heating rate of $10 \mathrm{~K} / \mathrm{min}$ and temperature range from 25 to $700{ }^{\circ} \mathrm{C}$. Mass of each sample was about $10 \mathrm{mg}$.

Dynamical mechanical analysis (DMA) was carried out using TA DMA Q800 analyzer. Measurements were performed with operating frequency of $10 \mathrm{~Hz}$. Samples were examined in temperature range from -120 to $150{ }^{\circ} \mathrm{C}$ with a heating rate of $4{ }^{\circ} \mathrm{C} / \mathrm{min}$. Rectangular shaped samples with dimensions of ca. $18 \times 10 \times 3 \mathrm{~mm}$ were used. The storage modulus $\left(\mathrm{E}^{\prime}\right)$, loss modulus $\left(\mathrm{E}^{\prime \prime}\right)$ and tan $\delta$ including glass transition temperature of elastic segments $\left(\mathrm{T}_{\mathrm{g}}\right)$ of partially bio-based polyurethanes were determined.

Hardness of obtained materials was examined in room temperature according to the PN-EN ISO 868:2005 with using Zwick/Roell HPE Shore D durometer. Each sample was tested ten times and the final results were averaged.

Tensile test in static conditions was performed in room temperature with using Zwick/Roell Z020 tensile-testing machine according to EN ISO 527-1:1996 and 5272:1996. Dumbbell-shaped samples of normal dimensions with $25 \mathrm{~mm}$ measuring section were stretched at a rate of $100 \mathrm{~mm} / \mathrm{min}$. Tensile strength $\left(\mathrm{R}_{\mathrm{m}}\right)$, elongation at break $\left(\varepsilon_{\mathrm{z}}\right)$, Young's modulus (E), stresses corresponding to 50\% 100\%, $200 \%$ and $300 \%$ of strain as a modulus elongation $\left(M_{50 \%}\right.$, $\mathrm{M}_{100 \%}, \mathrm{M}_{200 \%}, \mathrm{M}_{300 \%}$ respectively) as average of three measurements for ach sample determined.

Density of materials was determined by means of Radwag hydrostatic balance according to PN-EN ISO 1183-1:201306 . Measurements were conducted using methanol as an immersion liquid. The analysis was carried out in temperature of $24^{\circ} \mathrm{C}$. The results were determined as the average of three measurements for each sample.

Equilibrium swelling in toluene was performed according to the procedure described in PN-74/C-04236. The specimens with the average dimensions of $10 \times 10 \times 4 \mathrm{~mm}$ were weighted and then immersed in toluene. All the measurements were taken at room temperature for 7 days. During this period, at regular intervals, samples were taken out from toluene and weighted. On the basis of results, swelling index (S) was calculated, according to the Eq. (4):

$S=\frac{m_{1}-m_{0}}{m_{0}} * 100 \%$

where: $\mathrm{m}_{1}$-mass of sample after specified time of exposition in toluene $[\mathrm{g}], \mathrm{m}_{0}$-mass of sample before immersion in toluene $[\mathrm{g}]$.

\section{Results and Discussion}

\section{Fourier Transform Infrared Spectroscopy (FTIR)}

Fourier Transform Infrared Spectroscopy is widely used in the analysis of chemical structure of chemical compounds. In this work, the FTIR-ATR spectroscopy was conducted to indicate and confirm the presence of absorption peaks mandatory for urethane group in the structure of obtained materials. Based on the FTIR-ATR spectra (Fig. 1) main functional groups presented in the structure of partially 
Fig. 1 FTIR-ATR spectra of partially bio-based thermoplastic polyurethane elastomers obtained using diisocyanates mixtures

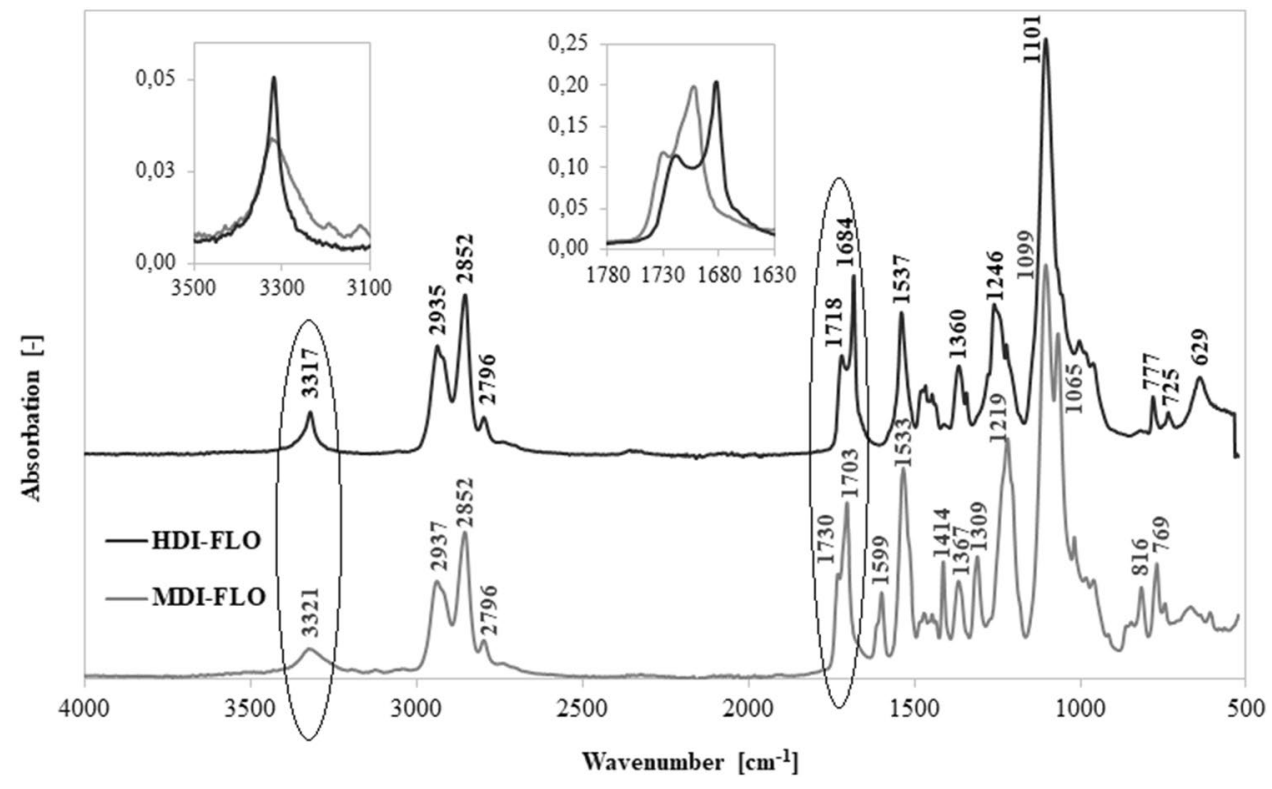

bio-based thermoplastic polyurethane elastomers were also recognized.

The FTIR-ATR spectra for both bio-PUs materials (MDIFLO and HDI-FLO) are similar taking into account the occurring of urethane group, but different in the intensity and small location shift of each absorption peaks. In both cases, peak at $2260 \mathrm{~cm}^{-1}$ wasn't observed, what confirmed that all of free-NCO groups reacted fully with low molecular weight chain extender as bio 1,3-propanediol [22, 23] Stretching vibrations of $-\mathrm{NH}$ groups occurred at $3321 \mathrm{~cm}^{-1}$ for sample MDI-FLO and 3317 for HDI-FLO, which indicates on the formation of hydrogen bonds in obtained partially bio-based polyurethanes [23, 24]. In the range of the stretching vibrations occurrence of $\mathrm{CN}$ bands are visible also the NH bending vibrations (II amide) at the wavenumber $1533 \mathrm{~cm}^{-1}$ for MDI-FLO and $1537 \mathrm{~cm}^{-1}$ for HDI-FLO $[23,25]$. The wavenumber range of $1730-1680 \mathrm{~cm}^{-1}$ was assigned to stretching vibrations of $\mathrm{C}=\mathrm{O}$ groups. Peaks have the form of multiplet, where higher wavenumbers from this range $\left(1730 \mathrm{~cm}^{-1}\right.$ for MDI-FLO, $1718 \mathrm{~cm}^{-1}$ for HDI-FLO) correspond to free $\mathrm{C}=\mathrm{O}$ groups and lower values $\left(1703 \mathrm{~cm}^{-1}\right.$ for MDI-FLO, $1684 \mathrm{~cm}^{-1}$ for HDI-FLO) to hydrogen-bonded $\mathrm{C}=\mathrm{O}$ groups in urethane groups. The shifting of $\mathrm{C}=\mathrm{O}$ peaks towards lower wavenumber in HDIFLO polyurethanes compared to MDI-FLO polyurethanes indicates greater number of hydrogen bonds that were created [22, 23]. It is in accordance with the analysis of intensity of peaks. As can be seen in Fig. 1 the intensity ratio of hydrogen-bonded to non-hydrogen-bonded peaks is higher for HDI-FLO polyurethanes, what confirms creation of higher amount of hydrogen bonds [26]. A wavenumber range of $1100-1000 \mathrm{~cm}^{-1}$ is attributed to the stretching vibrations of C-O-C groups. The region of $2780-2940 \mathrm{~cm}^{-1}$ indicates symmetric and asymmetric stretching vibrations of $\mathrm{C}-\mathrm{H}$ bonds, while the range of $1480-1300$ is assigned to deformation vibrations of the same bonds. thermoplastic polyurethane elastomers synthesized with using MDI-FLO mixture exhibited one additional peak at $1600 \mathrm{~cm}^{-1}$, which corresponds to stretching vibrations of aromatic ring bonds. The majority of corresponding peaks for both materials are slightly shifted. Presence of aromatic rings in polyurethanes synthesized with using MDI-FLO mixture causes slightly shifting the peaks locations to lower wavenumbers, comparing to bio-PUs based on HDI-FLO mixture.

Based on the FTIR spectra the degree of phase separation have been calculated as a ratio of carbonyl peak absorbance of bio-PU obtained using HDI-FLO mixture has higher

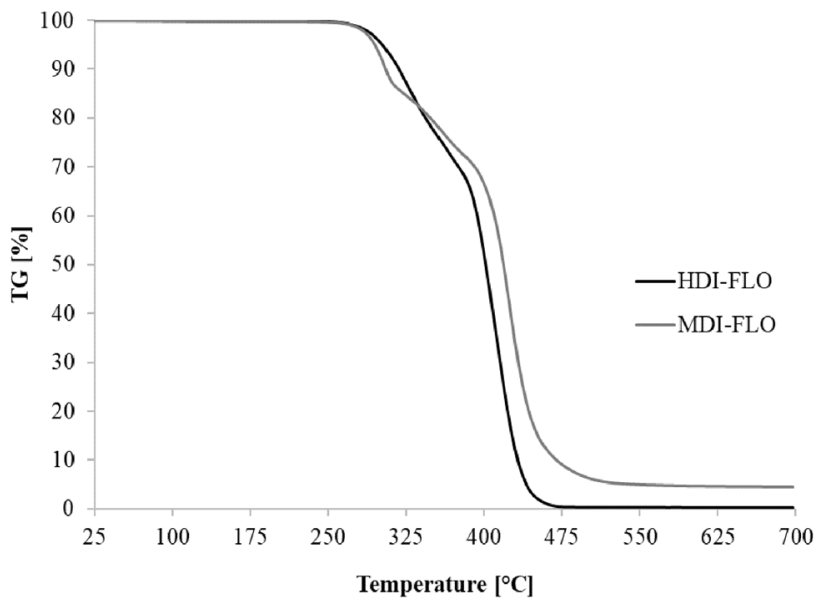

Fig. 2 TG curves of the partially bio-based thermoplastic polyurethane elastomers obtained using diisocyanates mixtures 


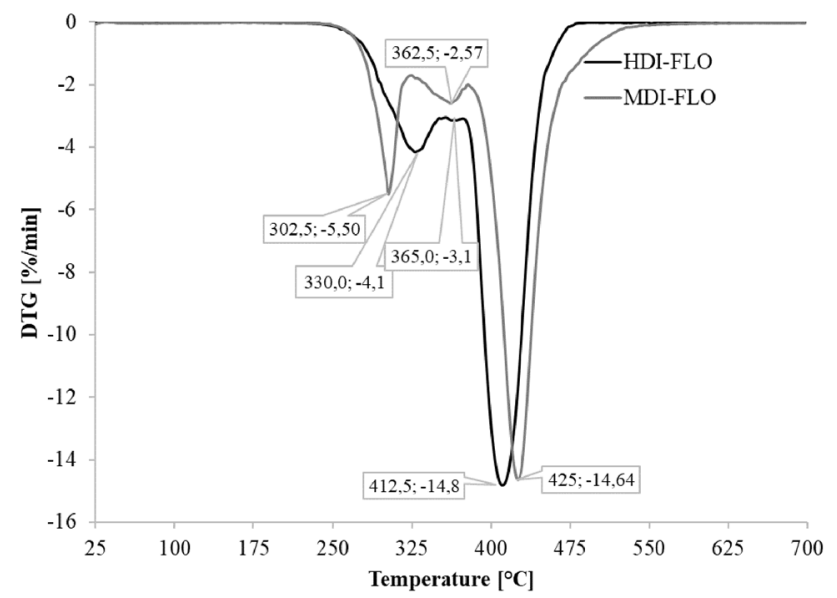

Fig. 3 DTG curves of the partially bio-based thermoplastic polyurethane elastomers obtained using diisocyanates mixtures.

index of degree of phase separation, DPS, ca.0.649 \pm 0.015 while bio-PU based MDI-FLO mixture ca. $0.29 \pm 0.002$.

\section{Thermogravimetric Analysis}

Thermogravimetric analysis (TGA) gives an information of thermal properties of the analyzed material, including the determination of temperature of beginning or rate of thermal degradation. In this work, TGA was used to indicate the differences in thermal properties of partially biobased thermoplastic polyurethane elastomers obtained using diisocyanates mixtures and determine the onset of thermal decomposition of obtained materials. Mostly, the thermal decomposition in the case of PUs occurs in two main steps and is related with the dissociation of urethane group and polyol residue and also pointed on the phase separation in the material [7, 27]. The onset and rate of the decomposition depend on many factors such type of used substrates in the synthesis of PU and their molar ratio. In the Figs. 2 and 3 TG and DTG curves were presented. It is visible that the thermal decomposition of partially bio-based polyurethanes obtained using diisocyanates mixtures took a place in the three stages. First and second step is related with the decomposition of hard segments of obtained partially bio-based polyurethanes, while the third step of soft segments. Depends on the type of diisocyante mixture (aliphatic-aliphatic or aromatic-aliphatic) the thermal stability of partially bio-based polyurethanes has been changed. Hard segments in the materials based on MDI-FLO mixture decomposed rapidly in lower temperature and higher rate than polyurethanes based on HDI-FLO mixture (Fig. 3). The two-step decomposition of hard segment is a consequent of the usage of diisocyanate mixture. In the chemical structure of FLO diisocyanate occurs the residue of fatty acid and the same is characterized by higher weight equivalent in comparison to petrochemical
Table 1 Tan $\delta, \mathrm{T}_{\mathrm{g}}$, E' and E" of partially bio-based thermoplastic polyurethane elastomers

\begin{tabular}{lllll}
\hline Sample & $\tan \delta_{\max }$ & $\mathrm{T}_{\mathrm{g}}\left[{ }^{\circ} \mathrm{C}\right]$ & $\begin{array}{l}\mathrm{E}^{\prime} \\
{[\mathrm{MPa}]}\end{array}$ & $\begin{array}{l}\mathrm{E}^{\prime \prime} \\
{[\mathrm{MPa}]}\end{array}$ \\
\hline HDI-FLO & 0,15 & -47.2 & 1776 & 115 \\
MDI-FLO & 0.38 & -34.7 & 2910 & 212 \\
\hline
\end{tabular}

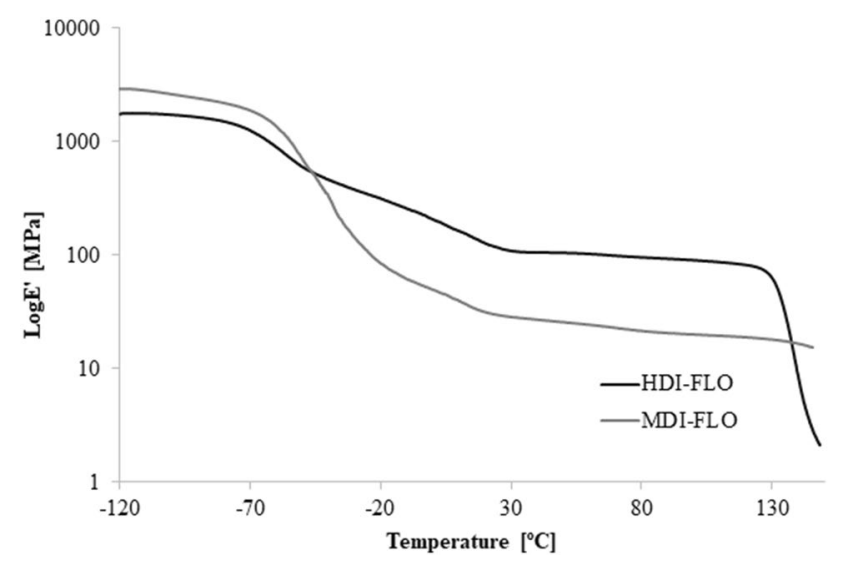

Fig. 4 The $\log \mathrm{E}^{\prime}$ as a function of the temperature of partially biobased thermoplastic polyurethane elastomers obtained using diisocyanates mixtures

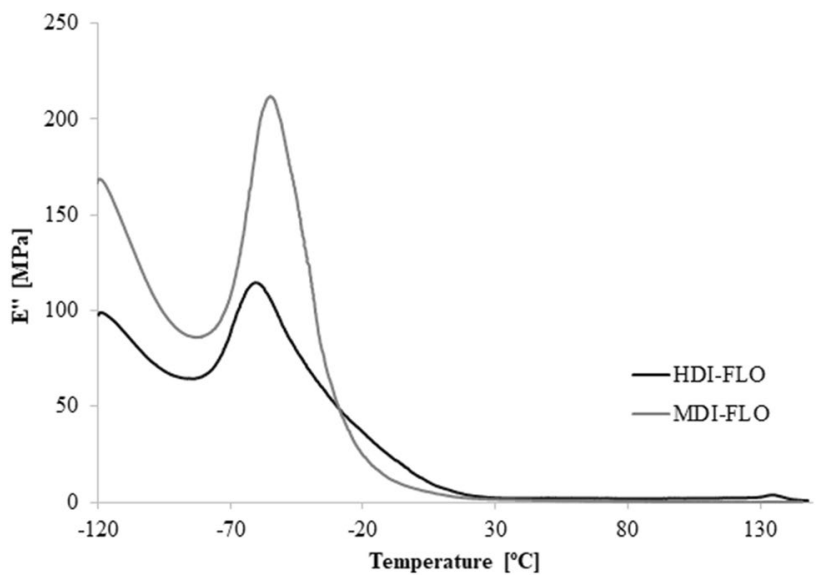

Fig. 5 The $E^{\prime \prime}$ as a function of the temperature of partially bio-based thermoplastic polyurethane elastomers obtained using diisocyanates mixtures

diisocyanates, the part of the hard segments build of FLO residue decomposed in higher temperature than hard segments build from HDI and MDI.

In the case of the decomposition of soft segments of bioPU based on MDI-FLO mixture the third step is shifted to the higher temperature with the comparable rate to the samples based on HDI-FLO mixture (Fig. 3). 


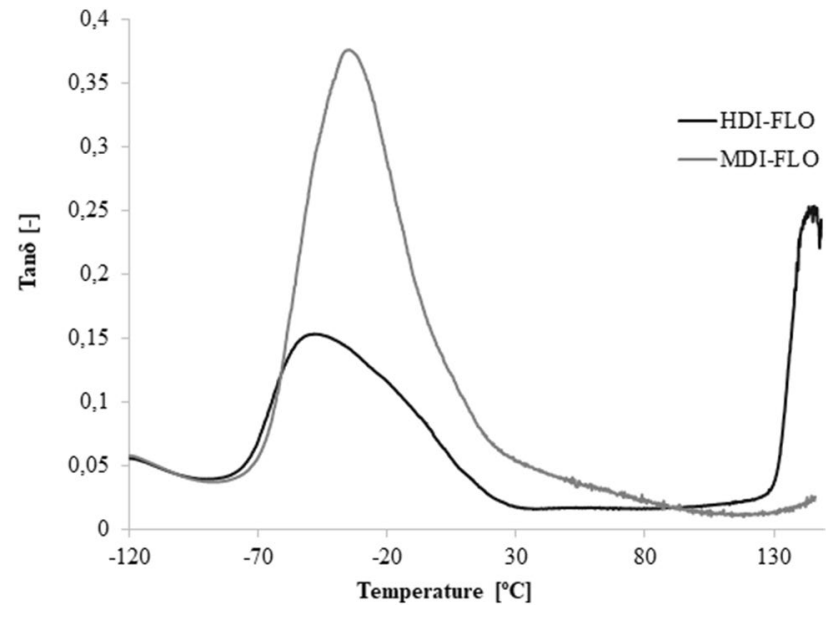

Fig. 6 Tan $\delta$ as a function of the temperature of partially bio-based thermoplastic polyurethane elastomers obtained using diisocyanates mixtures

\section{Dynamic Mechanical Analysis (DMA)}

Dynamical mechanical analysis provides a good deal of interesting information about material. On the basis of storage modulus $\left(E^{\prime}\right)$ the amount of energy accumulated in material and its stiffness can be defined. Loss modulus $\left(E^{\prime \prime}\right)$ informs about energy dissipated as a heat and loss factor $(\tan \delta)$ provides information about the macromolecular mobility [27]. Plots of storage modulus ( $\left.\mathrm{E}^{\prime}\right)$, loss modulus $\left(E^{\prime \prime}\right)$ and $\tan \delta$ as a function of temperature were presented in Figs. 5, 6 and 7, while maximum values of $\tan \delta, \mathrm{T}_{\mathrm{g}}$ (as the temperature at the maximum of $\tan \delta), \mathrm{E}^{\prime}$ and $\mathrm{E}^{\prime \prime}$ were presented in Table 1.

Analysis showed that type of diisocyanate mixture has an influence on thermomechanical properties of partially bio-based thermoplastic polyurethane elastomers. In the temperature range from -100 to $-50{ }^{\circ} \mathrm{C}$, significantly higher value of $\mathrm{E}^{\prime}$ is assigned to bio-PU based on MDIFLO (the difference is about $1134 \mathrm{MPa}$, see Table 1). In the case of both materials, temperature rise causes the drop of storage modulus, what is related to glass transition of soft segments of polyurethanes (Fig. 4). At the room temperature, polyurethanes obtained using HDI-FLO exhibit higher value of E' (about $100 \mathrm{MPa}$ ). Obtained results indicate that bio-PUs based on HDI-FLO possess greater capacity to accumulate energy and higher stiffness in room temperature. Above $100{ }^{\circ} \mathrm{C}$ for sample HDI-FLO it can
Table 3 The elongation modulus $\mathrm{M}_{50 \%}, \mathrm{M}_{100 \%}, \mathrm{M}_{200 \%}$ and $\mathrm{M}_{300 \%}$ of partially bio-based thermoplastic polyurethane elastomers obtained using diisocyanate mixtures

\begin{tabular}{lllll}
\hline Sample & $\mathrm{M}_{50 \%}[\mathrm{MPa}]$ & $\mathrm{M}_{100 \%}[\mathrm{MPa}]$ & $\mathrm{M}_{200 \%}[\mathrm{MPa}]$ & $\mathrm{M}_{300 \%}[\mathrm{MPa}]$ \\
\hline HDI-FLO & $6.3 \pm 0.1$ & $7.1 \pm 0.4$ & $8.8 \pm 0.2$ & $10.3 \pm 0.2$ \\
MDI-FLO & $4.6 \pm 0.1$ & $6.1 \pm 0.2$ & $8.5 \pm 0.2$ & $11.8 \pm 0.3$ \\
\hline
\end{tabular}

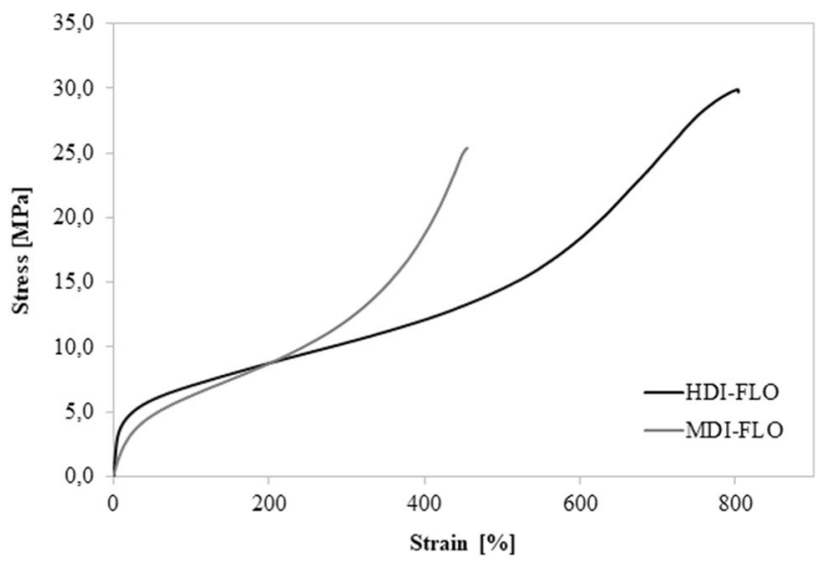

Fig. 7 Stress-strain curves of partially bio-based thermoplastic polyurethane elastomers obtained using diisocyanates mixtures

be observed rapid decreases in storage modulus which indicted on the thermoplastic character of this material and melting of hard segments.

The curves of loss modulus as a function of temperature display single peak in the temperature range from -70 to $-30{ }^{\circ} \mathrm{C}$ (Fig. 5). In this region, polyurethanes based on MDI-FLO exhibit higher E" about $60 \mathrm{MPa}$ than bio-PU based on HDI-FLO. It indicates that they are characterized by higher irreversible energy loss. In room temperature, values of loss modulus are nearly equal for both materials.

Loss factor $\tan \delta$ characterizes dumping properties of materials. It is calculated as a ratio of energy dissipated to energy accumulated in a process [28]. In the temperature range from -60 to $0{ }^{\circ} \mathrm{C}$, bio-PUs based on MDI-FLO exhibit nearly two times higher value of $\tan \delta$ that bio-PUs based on HDI-FLO (Fig. 6). It is connected with better dumping properties of this material [27]. On the basis of maximum of loss factor, glass transition temperatures $\left(\mathrm{T}_{\mathrm{g}}\right.$ ) of soft segments of polyurethanes were determined. In both cases these values are significantly lower than
Table 2 Results of mechanical analysis of partially bio-based thermoplastic polyurethane elastomers

\begin{tabular}{llllll}
\hline Sample & $\begin{array}{l}\mathrm{E} \\
{[\mathrm{MPa}]}\end{array}$ & $\mathrm{R}_{\mathrm{m}}[\mathrm{MPa}]$ & $\begin{array}{l}\varepsilon_{\mathrm{z}} \\
{[\%]}\end{array}$ & Hardness $\left[{ }^{\circ} \mathrm{Sh} \mathrm{D}\right]$ & Density $\left[\mathrm{g} / \mathrm{cm}^{3}\right]$ \\
\hline HDI-FLO & $80.1 \pm 10.5$ & $29.3 \pm 0.7$ & $813 \pm 8$ & $32.4 \pm 1.1$ & $1.051 \pm 0.002$ \\
MDI-FLO & $19.6 \pm 1.9$ & $26.0 \pm 3.1$ & $454 \pm 18$ & $27.5 \pm 1.2$ & $1.068 \pm 0.003$ \\
\hline
\end{tabular}




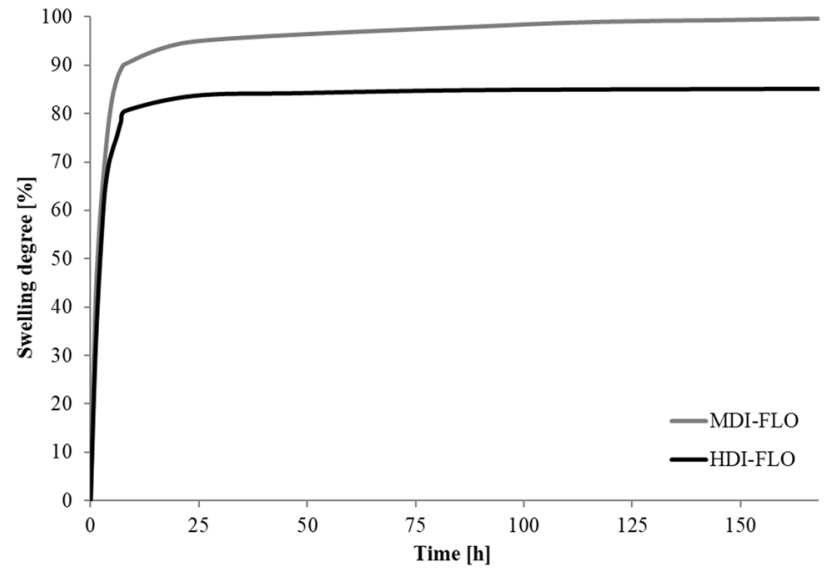

Fig. 8 Swelling degree as a function of time of partially bio-based thermoplastic polyurethane elastomers obtained using diisocyanates mixtures

room temperature, which is characteristic for elastomeric materials. HDI-FLO based PU exhibit elastic properties in the broader range of temperatures what was confirmed by lower value of glass transition temperature. Higher $\mathrm{T}_{\mathrm{g}}$ of bio-PU based on MDI-FLO indicated on increase phase mixing and poor phase separation between soft and hard segments in thermoplastic polyurethane elastomer what was also confirm by FTIR (DPS value) and thermogravimetric measurements.

\section{Mechanical Properties}

In order to determine the future application of new materials, tensile properties belong to the most crucial factors. The values of tensile strength $\left(\mathrm{R}_{\mathrm{m}}\right)$, elongation at break $\left(\varepsilon_{\mathrm{z}}\right)$, Young's modulus (E) and stresses corresponding to 50\%, 100\%, 200\% and $300 \%$ of strain $\left(\mathrm{M}_{50}, \mathrm{M}_{100}, \mathrm{M}_{200}, \mathrm{M}_{300}\right)$ were presented in Tables 2 and 3 evaluated, while the stress-strain curves were shown in Fig. 7.

In general, the type of diisocyanate mixture had a significant influence on the properties in tensile test. Bio-PU obtained using HDI-FLO mixture exhibited slightly higher value of tensile strength. Stresses at 50\%, 100\%, 200\% and $300 \%$ strain confirmed that this material is able to transfer higher loads at the same strain as bio-PU based on MDI-FLO (Tab.3). The results are in accordance with Young's modulus, which is the factor of proportionality between stress and strain in the resilience region. The Young's modulus value for polyurethanes obtained using MDI-FLO is lower about $60 \mathrm{MPa}$. These results were confirmed by DMA analysis at the room temperature region. Higher crosslinking density of HDI-FLO polyurethanes causes higher stiffness, tensile strength and Young's modulus at room temperature [7, 29]. Elongation at break was distinctly higher for HDI-FLO based
PU about $360 \%$ in accordance to MDI-FLO material. HDIFLO based polyurethanes also demonstrated higher percent of residual elongation. It means that polyurethanes obtained using HDI-FLO are capable of bigger deformations, but more percent of them are inelastic.

Difference between both materials is not so visible in terms of hardness and density. Densities of both materials are similar, at the range of 1.051-1.068 g/ $\mathrm{cm}^{3}$. HDI-FLO based bio-PU demonstrated hardness of $32.4{ }^{\circ} \mathrm{Sh} \mathrm{D}$ and MDI-FLO based bio-PU $27.5^{\circ} \mathrm{Sh} \mathrm{D}$, which is only $5^{\circ} \mathrm{Sh} \mathrm{D}$ lower.

\section{Equilibrium Swelling in Toluene}

Equilibrium swelling enables to determine the resistance of material to the specific solvent and in the case of crosslinked materials it helps to assess crosslinking density and molecular weight between nodes of network [30]. The swelling ratios of samples during exposition in toluene were presented in Fig. 8.

For both materials the similar weight changes have been observed. During first 2-3 h of bio-PU exposition in toluene the linear growth of the samples weight were noted. At that time, for MDI-FLO based PUs swelling degree was higher than for HDI-FLO based bio-PUs. After $25 \mathrm{~h}$ of exposition, saturation of toluene between polymer macromolecules is observed and the swelling ratios are almost constant.

Maximum swelling ratio is different for both materials. PUs based on MDI-FLO exhibit higher value ca. $99 \%$, while polyurethanes obtained with HDI-FLO have $\Delta \mathrm{m}=87 \%$. These results are correlated with crosslinking density of materials. The higher crosslinking density of material, the less space for solvent molecules to penetrate the network [31, 32]. That is the explanation why the swelling ratio is lower.

\section{Conclusion}

This work was connected with environmental friendly route for synthesis of novel bio-based thermoplastic polyurethane elastomers obtained by using diisocyanate mixtures which contained low volatility partially bio-based diisocyante derived from palm oil fatty acids. Partially bio-based thermoplastic polyurethane elastomers synthesized with using different diisocyanate mixtures were successfully prepared and analyzed. The results indicated that the type of diisocyanate mixture had an influence on the structure and properties of partially bio-based polyurethanes. Differences in structure were demonstrated on FTIR spectra especially in the wavenumber region of $1730-1680 \mathrm{~cm}^{-1}$. The shifting of $\mathrm{C}=\mathrm{O}$ peaks towards 
lower wavenumber in HDI-FLO bio-PU and intensity of them indicated greater number of hydrogen bonds that were created in this material. Generally bio-PU based on HDI-FLO diisocyanate mixture has higher thermal stability and decomposed at lower rate than the MDI-PU based PU what is advantage. DMA analysis showed that HDIFLO based polyurethanes exhibited greater capacity to accumulate energy and higher stiffness. They were also characterized by lower glass transition temperature and higher crosslinking density than MDI-FLO based bioPU, but possess worse dumping properties. Tensile test indicated that PUs obtained using HDI-FLO mixture have better mechanical properties. They exhibit higher tensile strength, modulus elongation at 50\%, 100\%, 200\% and $300 \%$, Young's modulus and elongation at break. Hardness and density of both type of bio-PU are similar. MDI-FLO based bio-PU was characterized by higher swelling degree in toluene than materials based on the HDI-FLO mixture.

Acknowledgements Diisocyanates (HDI and Tolonate ${ }^{\mathrm{TM}}$ X FLO 100) and bio based-1,3-propanediol (Susterra ${ }^{\circledR}$ Propanediol) were delivered by Vencorex Chemicals (France) and DuPont (USA). The authors wish to thank the aforementioned companies for kindly providing all components.

Funding This research did not receive any specific grant from funding agencies in the public, commercial, or not-for-profit sectors.

\section{References}

1. Akindoyo JO, Beg MDH, Ghazali S, Islam MR, Jeyaratnam N, Yuvaraj AR (2016) Polyurethane types, synthesis and applications-a review. RSC Adv 6(115):114453-114482

2. Agrawal A, Kaur R, Walia RS (2017) PU foam derived from renewable sources: perspective on properties enhancement: an overview. Eur Polym J 95:255-274

3. Li S, Jose J, Bouzidi L, Lopes A, Narine SS (2014) Maximizing the utility of bio-based diisocyanate and chain extenders in crystalline segmented thermoplastic polyester urethanes: effect of polymerization protocol. Polymer (Guildf) 55(26):6764-6775

4. Kaur R, Kumar M (2013) Function of silicon oil in the castor oil based rigid polyurethane foams. J Polym Eng 33(9):11-16

5. More AS, Lebarbé T, Maisonneuve L, Gadenne B, Alfos C, Cramail H (2013) Novel fatty acid based di-isocyanates towards the synthesis of thermoplastic polyurethanes. Eur Polym J 49(4):823-833

6. Parcheta P, Koltsov I, Datta J (2018) Fully bio-based poly(propylene succinate) synthesis and investigation of thermal degradation kinetics with released gases analysis. Polym Degrad Stab 151(February):90-99

7. Parcheta P, Głowińska E, Datta J (2020) Effect of bio-based components on the chemical structure, thermal stability and mechanical properties of green thermoplastic polyurethane elastomers. Eur Polym J 123:109422

8. Agrawal A, Kaur R, Walia RS (2019) Development of vegetable oil based conducting rigid PU foam. e-Polymers 19:411-420
9. Miao S, Wang P, Su Z, Zhang S (2014) Vegetable-oil-based polymers as future polymeric biomaterials. Acta Biomater 10(4):1692-1704

10. PUworld, Pure MDI price soars in winter, 2018. [Online]. Available: http://en.puworld.com/html/20180131/394776901.html. Accessed 20 Sep 2020

11. Jensen F (2020) OUTLOOK '20 Europe's polyurethane markets face a winter chill. [Online]. Available: https://www.icis.com/ explore/resources/news/2020/01/09/10458207/outlook-20-europ e-s-442polyurethane-markets-face-a-winter-chill. Accessed 20 Sep 2020

12. ICIS (2018) Isocyanates prices, markets \& analysis. [Online]. Available: https://www.icis.com/explore/commodities/chemicals/ isocyanates/. Accessed 20 Sep 2020

13. Charlon M, Heinrich B, Matter Y, Couzigné E, Donnio B, Avérous L (2014) Synthesis, structure and properties of fully biobased thermoplastic polyurethanes, obtained from a diisocyanate based on modified dimer fatty acids, and different renewable diols. Eur Polym J 61:197-205

14. de Guzman D (2015) 100\% bio-based Polyurethane in the market, Green Chemicals Blog. [Online]. Available: http://greenchemi calsblog.com/2015/04/27/100-bio-based-polyurethane-in-themarket/. Accessed 20 Sep 2020

15. Calvo-Correas T, Martin MD, Retegi A, Gabilondo N, Corcuera MA, Eceiza A (2016) Synthesis and characterization of polyurethanes with high renewable carbon content and tailored properties. ACS Sustain Chem Eng 4(10):5684-5692

16. Hojabri L, Kong X, Narine SS (2009) Fatty acid-derived diisocyanate and biobased polyurethane produced from vegetable oil: synthesis, polymerization, and characterization. Biomacromol 10(4):884-891

17. Hojabri L, Kong X, Narine SS (2010) Novel long chain unsaturated diisocyanate from fatty acid: synthesis, characterization, and application in bio-based polyurethane. J Polym Sci A 48:3302-3310

18. Zain NM, Roslin EN, Ahmad S (2016) Preliminary study on biobased polyurethane adhesive/aluminum laminated composites for automotive applications. Int $J$ Adhes Adhes 71:1-9

19. Yang CH, Yang HJ, Wen TC, Wu MS, Chang JS (1999) Mixture design approaches to IPDI-H6XDI-XDI ternary diisocyanatebased waterborne polyurethanes. Polymer (Guildf) 40(4):871-885

20. Prisacariu C, Scortanu E, Stoica I, Agapie B, Barboiu V (2011) Morphological features and thermal and mechanical response in segmented polyurethane elastomers based on mixtures of isocyanates. Polym J 43(7):613-620

21. Tolonate X FLO 100. [Online]. Available: https://www.palmerholl and.com/Assets/User/Documents/Product/44709/3831/MITM0 9115.PDF. Accessed 20 Sep 2020

22. Das S, Pandey P, Mohanty S, Nayak SK (2015) Influence of NCO/ $\mathrm{OH}$ and transesterified castor oil on the structure and properties of polyurethane: synthesis and characterization. Mater Express 5(5):377-389

23. Gurunathan T, Chung JS (2016) Physicochemical properties of amino-silane-terminated vegetable oil-based waterborne polyurethane nanocomposites.

24. Głowińska E, Datta J (2015) Structure, morphology and mechanical behaviour of novel bio-based polyurethane composites with microcrystalline cellulose. Cellulose 22(4):2471-2481

25. Głowińska E, Datta J, Włoch M, Różańska M (2018) The influence of chemical structure on mechanical and thermomechanical properties of cast biopolyurethane elastomers. Elastomery 22(1):40-50

26. Prociak A, Rokicki G, Ryszkowska J (2014) Materiały poliuretanowe. Wydawnictwo Naukowe PWN, Warszawa 
27. Głowińska E, Datta J, Parcheta P (2017) Effect of sisal fiber filler on thermal properties of bio-based polyurethane composites. J Therm Anal Calorim 130(1):113-122

28. Głowińska E, Datta J (2016) Bio polyetherurethane composites with high content of natural ingredients: hydroxylated soybean oil based polyol, bio glycol and microcrystalline cellulose. Cellulose 23(1):581-592

29. Głowińska E, Datta J (2016) Bio polyetherurethane composites with high content of natural ingredients: hydroxylated soybean oil based polyol, bio glycol and microcrystalline cellulose. Cellulose 23:581-592

30. Datta J, Parcheta P, Surówka J (2017) Softwood-lignin/natural rubber composites containing novel plasticizing agent: preparation and characterization. Ind Crops Prod 95:675-685
31. Fan Q, Xiao C (2008) Effects of crosslinking density on structure and properties of interpenetrating polymer networks from polyurethane and nitroguar gum. Polym Compos 29(7):758-767

32. Gu L, Wu Q-Y (2018) Recyclable bio-based crosslinked polyurethanes with self-healing ability. J Appl Polym Sci 46272:1-7

Publisher's Note Springer Nature remains neutral with regard to jurisdictional claims in published maps and institutional affiliations. 